\title{
Urdimento
}

\section{SEIS COISAS QUE SEI SOBRE 0 TREINAMENTO DE ATORES}

\author{
Anne Bogart ${ }^{1}$ \\ Tradução de Carolina Paganine ${ }^{2}$
}

\section{Resumo}

A partir da experiência de Anne Bogart como diretora, a pesquisadora propõe seis aspectos fundamentais que deveriam ser estimulados nos atores em um curso de interpretação. São eles: atitude, atenção, violência necessária, controle físico e expansão das emoções, desequilíbrio e desorientação, e interesse. Ao explicar cada um destes aspectos, Bogart questiona de que maneira eles podem ser ensinados a atores e mostra como são de uma importância crucial para o processo de criação de uma obra artística.

Palavras-chave: teatro, treinamento de atores, qualidades necessárias.

\begin{abstract}
From Anne Bogart's experience as a director, she proposes six necessary qualities that should be encouraged in actors in an acting program. They are attitude, attention, necessary violence, physical containment and emotional expansion, imbalance and disorientation, and interest. By explaining each one of them, Bogart questions how an actor can be taught those qualities and she also illustrates why they have a crucial importance to the process of creating an artistic work.
\end{abstract}

Keywords: theater, actor training, necessary qualities.

Não se pode treinar atores ou diretores para que sejam criativos, mas podemos ajudá-los a cultivarem seu eu artístico. Os jovens artistas precisam desenvolver uma relação bastante especial com o próprio trabalho. Se um programa de formação de ator não produz grandes atores, pode, através da prática e do exemplo, prepará-los para a vida de artista. O treinamento teatral pode estimular as seguintes qualidades necessárias a cada indivíduo:

$$
\begin{array}{ll}
\text { 1. } & \text { Atitude } \\
\text { 2. Atenção } \\
\text { 3. Violência necessária }
\end{array}
$$

${ }^{1}$ Anne Bogart é diretora artística da SITI Company, fundada juntamente com o diretor japonês Tadashi Suzuki em 1992. É professora da Columbia University, onde leciona no Graduate Directing Program.

${ }^{2}$ Carolina Paganine é tradutora formada pela Universidade de Brasília (2004), doutoranda em Estudos da Tradução na Universidade Federal de Santa Catarina. 


\section{Urdimento}

4. Controle físico e expansão das emoções

5. Desequilíbrio e desorientação

6. Interesse

\section{1) Atitude}

A atitude de uma pessoa frente a qualquer tarefa é determinante para que haja bons resultados. Atitude é fundamental. Como diz o artista plástico Christo, "não existem problemas, apenas situações”. Chamar algo de problema dá origem a uma relação equivocada com o que está acontecendo, predeterminando uma atitude pessimista e de início derrotista. É muito importante a atitude que trazemos para uma peça, um papel, um ensaio ou um relacionamento.

Podemos treinar atitudes? Podemos treinar a atitude que um ator traz para um ensaio ou para sua própria carreira?

Recentemente, comecei a entender o conceito de gestus de Bertolt Brecht. Gestus não é um gesto, como pensava antes, mas, na verdade, parece que gestus se refere à atitude. Brecht acreditava que o ator deveria se preocupar em não expressar sentimentos, mas “mostrar atitudes” ou gesten.

Uma atitude é uma energia direcionada ao exterior. Se me sinto atraída por alguém, minha energia direcionada ao exterior é bastante específica e minhas respostas flutuam de acordo com a maneira que esta pessoa se relaciona comigo. Todas as minhas escolhas físicas, vocais e temporais são feitas em relação ao meu objeto de interesse. Quando o interesse acaba, a atitude muda. Em qualquer ocasião, minha atitude revela intenção e finalidade.

Os japoneses possuem uma palavra para descrever a qualidade de espaço e tempo entre as pessoas: ma'ai. Nas artes marciais, o ma'ai é de fundamental importância por causa do perigo de um ataque mortal. No palco, o espaço entre os atores também deveria ser continuamente dotado de qualidade, atenção, potencial e até mesmo perigo. O ma'ai deve ser cultivado, respeitado e estimulado. As linhas de tensão entre os atores no palco nunca deveriam se afrouxar.

Uma vez conversei com um ator que interpretava Nick em Quem tem medo de Virginia Woolf? com Glenda Jackson representando o papel de Martha. Ele disse que a atriz nunca, nunca mesmo, deixou a linha entre ela e os outros três atores se afrouxar. A tendência com um ator menor, interpretando um personagem alcoólico e libertino, próximo ao caos, seria atenuar a tensão e se afundar no sofá. Mas com Jackson, as linhas de tensão entre ela e os outros tinham que ser produzidas a cada momento. Somente quando ela deixava o palco é que essas linhas se soltavam. 


\section{Urdimento}

Os alemães usam a palavra Haltung ou seu plural Haltungen para descrever as posturas em constante mudança que tomamos em relação a uma pessoa, uma tarefa ou um objetivo. Em inglês, a palavra attitude é, em geral, vista como negativa - "I don't have an attitude" ("Eu não sou prepotente") ${ }^{3}$. As pessoas querem evitar que sejam vistas como "sendo prepotentes". Gostaria de sugerir que todo trabalho começa com uma atitude frente a esse trabalho. Cada personagem e cada situação se tornam especiais através de uma sinfonia de atitudes que se modificam.

\section{2) Atenção}

Eu ensino direção teatral na Universidade de Columbia. A única coisa que sei sobre dirigir é que dirigir diz respeito a escutar. Como ensinar a escuta? Como se aprende sobre atenção?

Como diretora, minha maior contribuição para uma produção, a única coisa que posso oferecer de verdade a um ator, é a minha atenção. $\mathrm{O}$ que mais conta é a qualidade desta atenção. Com que parte de mim estou assistindo? Estou assistindo desejando bons resultados da peça ou assisto interessada no momento presente? Espero o melhor do ator ou quero provar minha superioridade? Um bom ator pode rapidamente discernir a qualidade da minha atenção, do meu interesse. Há uma linha de vida sensível entre nós. Se esta linha é comprometida, o ator sente. Se for depreciada pelo meu próprio ego, desejos ou falta de paciência, a linha entre nós estará deteriorada.

Ensaiar não é forçar que as coisas aconteçam, mas sim escutá-las. O diretor escuta os atores. Os atores escutam uns aos outros. Escuta-se coletivamente o texto. Escutamos em busca de indícios. Mantemos as coisas em movimento. Investigamos. Não se ameniza os momentos como se tudo estivesse entendido. Nada ficou entendido. Trazemos nossa atenção para a situação enquanto esta se desenrola. Penso que o ensaio é como brincar com o Tabuleiro Ouija em que todos colocam as mãos sobre uma pergunta e depois seguem o movimento quando este começa a se revelar. Segue-se o movimento até que a cena libere seu segredo.

Atenção significa tensão - uma tensão entre um objeto e um observador ou tensão entre pessoas. É um modo de escutar. Atenção é uma tensão sobre tempo.

\section{3) Violência necessária}

O treinamento deveria ensinar ao ator a necessidade de violência em um ato criativo.

Março $2009-\mathrm{N}^{\circ} 12$

Seis coisas que sei sobre o treinamento de atores. Anne Bogart
3 Em inglês, a palavra attitude pode conter uma acepção negativa de exacerbada autoconfiança. Já em português, é preciso adjetivar o cognato "atitude" como em "atitude ruim, hostil" ou substituí-la por outra palavra como "arrogante" ou "prepotente", de acordo com 0 contexto. (N. da T.) 


\section{Urdimento}

${ }^{4}$ Em inglês, keep $i t$, que pode ser traduzido também por outras expressões equivalentes usadas no Brasil como: "é isto", "esta é a cena", ou "mantenha isto". (N. da T.)

A arte é violenta. Tomar uma decisão é um ato violento. Antonin Artaud definiu a crueldade como "uma determinação, uma persistência, um rigor incansáveis". Colocar uma cadeira em uma posição específica no palco acaba com todas as outras escolhas possíveis, todas as outras opções. Quando um ator atinge um momento espontâneo, intuitivo ou passional no ensaio, o diretor profere as palavras fatídicas: "guarda isso", eliminando todas as outras soluções em potencial. Estas duas palavras cruéis, "guarda isso", enfiam uma faca no coração do ator que sabe que a próxima tentativa de recriar aquele resultado será falsa, afetada ou sem vida. Mas, bem no fundo, o ator também sabe que a improvisação ainda não é arte. Somente quando algo foi decidido que o trabalho pode realmente começar. A determinação e a crueldade, que extinguiram a espontaneidade do momento, exigem que o ator comece um trabalho extraordinário: ressuscitar os mortos. $\mathrm{O}$ ator deve agora encontrar uma espontaneidade nova e mais profunda dentro desta forma estabelecida. Para mim, é por isto que os atores são heróis. Eles aceitam esta violência e trabalham com ela, trazendo habilidade e imaginação à arte da repetição.

É significativo que a palavra francesa para ensaio seja repetition. Decerto, pode-se argumentar que a arte teatral é a arte da repetição. (A palavra inglesa rehearsal / "ensaio", ou re-hear, propõe "ouvir de novo". A alemã Probe sugere investigação. Em japonês, keiko se traduz como prática. E por aí vai. Um estudo sobre as palavras para "ensaio" nas diferentes línguas é infinitamente fascinante.) No ensaio, o ator busca por formas que podem ser repetidas. Juntos, atores e diretores constroem uma estrutura que dará margem a infinitas novas correntes de força vital, vicissitudes emocionais e conexão com os outros atores. Gosto de pensar sobre a encenação, ou sobre o bloqueio, como um veículo em que os atores podem se mover e crescer. Paradoxalmente, são as restrições, a precisão e a exatidão que permitem a possibilidade de liberdade. A forma se torna um recipiente no qual o ator encontra variações infinitas e liberdade interpretativa.

Para o ator, esta violência necessária ao criar um personagem para o teatro é bastante diferente da violência necessária ao atuar para a câmera. $\mathrm{Na}$ atuação para o cinema, o ator pode se permitir fazer algo impulsivo sem se preocupar em repeti-lo inúmeras vezes. O essencial para a câmera é que o momento seja espontâneo e fotogênico. No teatro, é preciso que seja repetível.

Percebi pela primeira vez a necessidade de violência no ato criativo enquanto assistia o diretor Robert Wilson ensaiar Hamletmachine de Heiner Müller com estudantes de graduação de Artes Cênicas na Universidade de Nova Iorque. O ensaio estava marcado para começar às 19h. Cheguei mais cedo e me deparei com um clima alegre. Na última 


\section{Urdimento}

fileira do teatro, estudantes de pós-graduação e outros pesquisadores esperavam ansiosos, com as canetas na mão, pela chegada de Wilson. No palco, os jovens atores se aqueciam. Uma equipe de administração cênica estava sentada atrás de um batalhão de mesas compridas, colocadas na extremidade do palco. Wilson chegou às $19 \mathrm{~h} 15$. Sentou-se no centro da arquibancada em meio ao alvoroço e ao barulho e começou a olhar atentamente para o palco. Aos poucos, todos no teatro se aquietaram até que o silêncio fosse cortante. Depois de cerca de cinco minutos torturantes em completa quietude, Wilson se levantou, caminhou até uma cadeira no palco e ficou encarando-a. Depois do que me pareceu uma eternidade, ele se abaixou, tocou a cadeira e a moveu menos de três centímetros. Quando ele deu um passo para trás para olhar a cadeira de novo, percebi que eu estava com dificuldade para respirar. A tensão no recinto era palpável, quase insuportável. Em seguida, Wilson acenou para que uma atriz se aproximasse a fim de lhe mostrar o que queria que ela fizesse. Fez uma demonstração sentando na cadeira, se inclinando para frente e movendo ligeiramente os dedos. Então, ela assumiu o lugar dele e copiou, de modo preciso, a inclinação e os gestos com a mão. Percebi que me curvava para a frente na minha própria cadeira, profundamente angustiada. Senti-me como se estivesse assistindo outras pessoas em uma situação privada e íntima. Naquela noite, reconheci a crueldade necessária da decisão.

$\mathrm{O}$ ato determinado de posicionar um objeto em uma posição precisa no palco, ou o gesto de mão de um ator, me parecia quase um ato de violação. Para mim, isto era perturbador. Entretanto, no fundo eu sabia que este ato violento é uma condição necessária para todos os atores.

A violência começa com a tomada de decisão, com um comprometimento com alguma coisa. A palavra commit $^{5}$ vem do Latim committere, que significa "inflamar uma ação, unir, juntar, confiar e fazer". Comprometer-se com uma escolha parece violento. É como a sensação de pular de um enorme trampolim. Parece violento porque tomar uma decisão é uma agressão contra a natureza e a inércia. Mesmo uma escolha aparentemente tão pequena quanto decidir a posição precisa de uma cadeira parece uma violação do fluxo livre e do curso da vida.

Para gerar a excitação indispensável, é preciso que haja algo em jogo, em risco, algo momentâneo e incerto. A certeza não nos estimula emocionalmente.

Grandes interpretações exalam exatidão e uma sensação poderosa de liberdade. Esta liberdade só pode ser encontrada dentro de certas limitações escolhidas. As limitações servem como uma lente para focar e ampliar o evento para o público, bem como para dar aos atores algo com o que se compararem. Uma limitação pode ser algo simples como permanecer na luz correta e falar o texto exatamente como está escrito ou tão difícil quanto interpretar uma
${ }^{5}$ Dependendo do contexto commit pode ser "comprometer-se" ou "cometer" em português. (N. da T.) 


\section{Urdimento}

coreografia complexa ao mesmo tempo em que se canta uma ária. Estas limitações convidam o ator a conhecê-las, a perturbá-las, a transcendê-las. O público presencia o ator testando seus próprios limites, expressando algo além do banal apesar das limitações.

Ser bem articulado diante das limitações é o lugar onde a violência se instaura. Este ato de violência necessária, que à primeira vista parece limitar a liberdade e reduzir as opções, por sua vez, abre muito mais opções e demanda do artista um sentido mais profundo de liberdade.

A resistência fortalece e intensifica o esforço. Encontrar resistência, confrontar um obstáculo ou superar uma dificuldade sempre demanda criatividade e intuição. No centro do conflito, tem-se que apelar para novas reservas de energia e de imaginação. Desenvolvemos os músculos no ato de superar a resistência - nossos músculos artísticos. Como um bailarino, é preciso exercitar regularmente para manter a musculatura. A magnitude das resistências que se escolhe empregar determina a progressão e a profundidade do trabalho. Quanto maiores os obstáculos, mais coisas poderemos transformar com o esforço.

\section{4) Controle físico e expansão das emoções}

Um grande ator, assim como uma excelente dançarina de striptease, se refreia mais do que mostra. Com a maturidade, os artistas se aproximam da grande sabedoria encontrada na combinação poderosa entre o controle físico e a expansão das emoções. O refreamento é fundamental. Pegue o momento e todas as suas complexidades, concentre-o, deixe-o acontecer e, então, o guarde. Concentrar e refrear geram energia no ator e interesse no público. Zeami, o criador japonês do teatro Nô, sugeria que o ator deveria sempre conter um certo percentual de suas emoções: "Quando sentir dez no coração, expresse sete...”.

O talento mais especial de um ator é a capacidade de resistir, de conter, de domar, de conservar a energia em si, de concentrar. Com esta compressão, o ator brinca com a sensibilidade cinestésica dos espectadores e evita que eles prevejam o que está para acontecer. A cada instante, o objetivo é esconder do espectador a estrutura predeterminada e o desfecho.

Pouco tempo atrás, ao visitar o Museu de Arte Moderna de São Francisco, me deparei com uma pintura gigantesca de Anselm Kiefer, intitulada Osiris and Isis. Meus planos de visitar todo o museu naquele dia foram por água abaixo. Não conseguia dar as costas a este quadro intenso, belo, vibrante, perturbador e inabandonável. Fui confrontada pela magnitude de suas idéias, formas, violência, movimento e perspectivas infinitas que se abriram quando me deparei com este trabalho. Detida no meu caminho, não podia passar pelo quadro e prosseguir para as outras pinturas. Tinha que conhecê-lo, lidar com ele. Fui desafiada e isto me transformou. 
O que nos detém no caminho? É raro que eu seja detida por alguma coisa ou por alguém que consigo compreender de imediato. Na verdade, sempre me senti atraída pelo desafio de passar a compreender aquilo que não consigo categorizar ou abandonar rapidamente, seja a presença de um ator, uma pintura, uma música ou uma relação pessoal. É a jornada em direção ao objeto de atração que me interessa. Vivemos em relação uns com os outros. Ansiamos pelos relacionamentos que mudarão nossas perspectivas. A atração pelo outro é um convite a uma jornada que mudará nossas vidas, a um novo modo de experienciar a vida ou perceber a realidade.

Uma obra de arte autêntica incorpora uma energia intensa. Exige uma resposta. Pode-se tanto evitá-la ou trancá-la, quanto encará-la e confrontá-la. Ela contém campos de energia atraentes e complicados, além de uma lógica própria. Não gera desejo ou movimento no receptor, mas produz o que James Joyce chamou de "imobilização estética". No meio do caminho, você é detido. Não se pode passar facilmente por ela e dar continuidade à vida. Você se encontra em relação com algo que não consegue abandonar de imediato.

Em Retrato do artista quando jovem, James Joyce diferencia a arte estática da cinética. Ele aprecia a arte estática e despreza a arte cinética. Acredito que este conceito de estático e cinético seja desafiador e útil para se pensar sobre o que colocamos no palco. A arte cinética o faz mover. A arte estática o faz parar. A pornografia, por exemplo, é cinética - ela pode te excitar sexualmente. A publicidade é uma arte cinética — pode induzi-lo a comprar. A arte política é cinética - pode movê-lo para a ação política. Por outro lado, a arte estática o detém. Causa uma parada. Assim como a pintura de Anselm Kiefer, não o deixará passar tranquilamente por ela. A arte estática oferece um universo auto-suficiente, unificado somente em seus campos complexos e contraditórios. Não o fará lembrar-se de nenhuma outra coisa. Não desperta desejos e não o move de uma maneira tranquila. Você é detido em seu caminho por este poder extraordinário. Ao se confrontar com as maravilhosas pinturas de maçãs de Cézanne, por exemplo, não se deseja comer as maçãs. Você, ao contrário, é confrontado pela maçanidade das maçãs! Elas o detêm em seu caminho.

Com Osiris and Isis, fui detida pela magnitude do drama interior específico desta pintura. Ela me convidou a lidar com ela. Fui chamada para a aventura que é uma relação.

Um bom ator me detém em meu caminho. É difícil não considerar a qualidade de seu silêncio, movimento ou fala. Embora eu não esteja consciente do que é isso que eles fazem para produzir essa presença magnética, sei que não consigo desviar os olhos. Não posso seguir adiante. 


\section{Urdimento}

${ }^{6}$ Neste caso, "discussão", "confrontação" em português. (N. da T.).
O que o ator faz para me deter em meu caminho? Como treinamos um ator para que monte os campos de energia necessários para nos deter? O que eu de fato sei é que um ator estrutura uma paisagem interna complexa e tenta permanecer presente dentro dela. $\mathrm{O}$ ator põe em prática, simultaneamente, as muitas linguagens do palco, incluindo o tempo, espaço, texto, ação, personagem e história. A realização disso tudo é um feito extraordinário de malabarismo com diversas coisas ao mesmo tempo. A fala se torna dramática por causa da mudança que ocorre dentro da pessoa que está presente, no momento, envolvida com o discurso. E eu também estou presente ali, em relação com esta pessoa fazendo malabarismos.

A vitalidade na arte é o resultado da articulação, da energia e da diferenciação. Toda grande arte é uma arte diferenciada. O ofício do ator está na diferenciação de um momento do outro que se segue. Um grande ator aparenta ser perigoso, imprevisível, cheio de vida e diferenciação.

A qualquer momento um ator se depara com um dilema em particular: escolher entre desfazer-se da experiência ou concentrá-la. É fácil se desfazer. É só deixar ir, deixar fluir sempre que se sentir cheio. Mas acredito que é importante para um ator aprender a necessidade de concentrar as irritações, os sentimentos aleatórios, as dificuldades, as paixões, tudo que acontece de momento a momento, para depois comprimi-los, deixá-los acontecer e encontrar os momentos adequados para a expressão clara e articulada. O resultado será uma expressão e não um desfazimento aleatório.

Os americanos foram infestados pela doença da concordância. No teatro, supomos frequentemente que colaborar significa concordar. Acredito que concordância demais resulta numa falta de vitalidade. Concordar sem refletir esfria a energia no ensaio. Não acredito que colaboração implica em fazer mecanicamente o que o diretor manda. Sem resistência não há fogo. Os alemães têm uma palavra bastante útil que não tem um equivalente adequado em inglês: auseinandersetzung. A palavra, que literalmente quer dizer "colocarse em oposição a outra pessoa", é em geral traduzida para o inglês como argument $^{6}$, por via de regra uma palavra de conotações negativas. Embora um ambiente descontraído e agradável no ensaio me deixe bastante feliz, meu melhor trabalho emana do auseinandersetzung, o que significa para mim que durante o ato criativo precisamos nos colocar em oposição uns aos outros. Significa que nos atacamos mutuamente de maneira produtiva, que talvez entremos em embate; significa que poderemos discutir, discordar um do outro, oferecer alternativas. Significa que conviveremos com uma discordância irritante e uma atmosfera animada. 
É nossa obrigação treinar o ator para que preserve presença e intensidade suficientes para colidir em vez de concordar com tudo no ensaio. Em lugar de seguir cegamente as instruções, o ator deveria trazer seu próprio calor, inteligência, sensibilidade estética e intuição para o processo. Descobri que os atores de teatro alemães tendem a trabalhar com auseinandersetzung em demasia, o que se torna debilitante e pode originar produções estáticas e impetuosas. Os americanos tendem mais para a concordância, o que pode dar margem a uma arte superficial, não-investigativa e simplista.

\section{5) Desequilíbrio e desorientação}

Todo ato criativo requer um salto no vazio. O salto tem que ocorrer no momento certo e, no entanto, a hora de saltar nunca será estabelecida de antemão. Não há garantias quando se está no meio do salto. Em geral, saltar causa uma perplexidade extrema. A perplexidade é uma parceira no ato criativo — uma colaboradora fundamental. Se o seu trabalho não o deixa suficientemente perplexo, então é bastante provável que não comoverá ninguém.

Podemos instilar em um jovem ator a consciência da necessidade imperativa de desequilíbrio e desorientação no processo criativo?

A maioria das pessoas se torna altamente criativa em meio a uma situação de emergência. No momento do desequilíbrio e da pressão, precisamos encontrar soluções rápidas e satisfatórias para grandes problemas repentinos. São nestes momentos de crise que a inteligência inata e a imaginação intuitiva entram em jogo: a mulher que levanta um carro porque seu filho está preso embaixo, uma escolha estratégica e inspirada durante a crise de uma batalha, decisões rápidas no calor de um ensaio final antes da estréia para o público. Tenho descoberto que, do ponto de vista da criação, o desequilíbrio é mais frutífero que a estabilidade.

A arte começa na luta por equilíbrio. Não se consegue criar em um estado de harmonia. Estar fora do equilíbrio produz um estado que é sempre interessante no palco. No momento do desequilíbrio, nossos instintos animais nos impelem a lutar pelo equilíbrio e esta luta é infinitamente cativante e proveitosa. Quando passar a acolher o desequilíbrio em seu trabalho, você ficará imediatamente cara a cara com sua própria propensão ao hábito. O hábito é um adversário do artista. Em arte, a repetição inconsciente de um território familiar nunca é vital ou estimulante. Precisamos tentar permanecer atentos e vivos ao nos depararmos com nossas propensões ao hábito. Encontrarse em situação de desequilíbrio lhe apresenta um convite à desorientação e à dificuldade. Não é uma situação confortável. De repente, você se sente 


\section{Urdimento}

deslocado e fora de controle. É aqui que a aventura começa. Quando se acolhe o desequilíbrio, você entrará imediatamente em um território novo e desconhecido onde se sentirá pequeno e inadequado em relação à tarefa por fazer. Mas os frutos deste compromisso serão abundantes.

Toda grande jornada começa com desorientação. As crianças naturalmente giram umas as outras, de olhos vendados, antes de uma brincadeira. Alice cai no buraco do coelho e muda de tamanho ou viaja por um espelho para chegar ao País das Maravilhas. Nós todos, público e artistas, temos que dar chance a um pouco de desorientação pessoal a fim de abrir caminho para a experiência.

Tenho medo de cair. Passei anos estudando a arte marcial japonesa Aikido por causa da quantidade de tempo que se passa de cabeça para baixo durante a prática. Tento acolher a desorientação como uma prática necessária ao meu trabalho nos ensaios. Sei que tenho que aprender a acolher a desorientação e o desequilíbrio. Sei que a tentativa de encontrar equilíbrio a partir de um estado de desequilíbrio será sempre produtiva e interessante e renderá ótimos resultados. Tento acolher a desorientação para dar chance ao amor verdadeiro.

Apaixonar-se é desorientador porque os limites entre os recémenamorados não foram demarcados. Para nos apaixonar, temos que nos desapegar de hábitos cotidianos. Para sermos tocados, temos que estar dispostos a não saber como será a sensação do toque. Um grande espetáculo de teatro também é desorientador porque as fronteiras entre quem dá e quem recebe não são claras. Um artista que emociona joga com as nossas expectativas e com nossa memória. Este intercâmbio possibilita uma experiência artística interativa e viva.

No ensaio e na apresentação, é necessário saltar a cada momento. Toda vez que um ator pisa no palco, ele precisa estar preparado para saltar inesperadamente. Sem esta predisposição, o palco continuará a ser um lugar monótono e convencional. Se ficar preparado para saltar no momento adequado, nunca saberá quando será este momento. A porta se abre e você tem que passar por ela sem pensar nas consequências. Você salta. Mas também terá que aceitar que o salto, por si mesmo, não é garantia de nada. Ele não suaviza a perplexidade, mas sim a acentua.

De acordo com Rollo May em seu livro The courage to create (A coragem para criar), durante toda a história artistas e cientistas concordaram que, em seus melhores momentos, eles sentem como se algo se manifestasse através deles. De alguma maneira, conseguiram desembaraçar o próprio caminho. Alguns dizem que Deus se manifesta através deles. De maneira mais modesta, outros afirmam que, a fim de desembaraçar o próprio caminho e desviar do 
lobo frontal do cérebro, saem para dar uma volta na floresta ou tiram um cochilo. Eles têm que desligar a mente do que estão tentando fazer para que possam produzir conexões mais inspiradas. A mente está sempre preparada para emboscar o processo. As descobertas e inovações acontecem quando você consegue desembaraçar o próprio caminho.

Os encontros com a resistência e a compressão de emoções geram uma das condições mais cruciais para o teatro: energia. A energia é gerada quando se assume a responsabilidade com a cara e a coragem e se supera o obstáculo. $\mathrm{O}$ êxito de um ator é proporcional à qualidade da interação com a resistência inesperada da situação. A oposição entre uma força que impele para a ação e outra força que a retém é traduzida pela energia visível e sensível no espaço e no tempo. Esta luta pessoal com o obstáculo, por sua vez, leva ao desacordo e ao desequilíbrio. A tentativa de restabelecer a harmonia a partir deste estado de agitação gera ainda mais energia. Esta batalha é, em sim mesma, o ato criativo.

É natural e humano buscar a união e restabelecer o equilíbrio após o desequilíbrio do compromisso com a discordância. Recite um solilóquio inteiro de Shakespeare a partir de um estado físico de desequilíbrio. $\mathrm{Na}$ tentativa de manter o equilíbrio e não cair enquanto fala, cada pedaço de seu ser busca o equilíbrio, a harmonia e a união. Esta luta é positiva e produtiva. De súbito, o corpo fala com uma clareza e uma necessidade surpreendentes. A luta exige precisão e articulação.

Um eu artístico é aquele que acolhe o desequilíbrio e a desorientação.

\section{6) Interesse}

O interesse é a ferramenta fundamental no processo criativo. Para ser fiel a um interesse e persegui-lo, o melhor barômetro é o corpo. O coração acelera. A pulsação fica apressada. O interesse pode ser o seu guia. Sempre apontará para a direção certa. Ele define a qualidade, a energia e o conteúdo do trabalho. Não se pode fingir ou dissimular o interesse ou mesmo escolher sentir-se interessado por alguma coisa só porque foi recomendado. O interesse nunca poderá ser recomendado. Ele é uma descoberta. Quando sentir esta aceleração, você tem que agir de imediato. Terá que seguir este interesse e segurá-lo firme.

Nos momentos em que o interesse desperta, quando você se encontra detido em seu caminho, perceberá imediatamente que está em uma encruzilhada. Nestas encruzilhadas, as definições e os princípios que o formaram e o guiaram até o momento presente se desintegram; o que fica é um sentimento de desorientação, uma animação descontrolada, uma sensação de falar livre e espontaneamente, um interesse. 


\section{Urdimento}

Se o interesse for genuíno e grande o bastante e se for perseguido com tenacidade e generosidade, o efeito bumerangue será evidente. O interesse devolve a bola sem deixá-la cair no chão, afetando sua vida e a alterando de maneira inevitável. É preciso que se esteja disponível e atento às portas que se abrem de repente. Não se pode demorar. As portas se fecham rápido. Mudará a sua vida. Surgirão aventuras que você nunca imaginou. Terá que ser fiel ao interesse e ele lhe será fiel.

O maior inimigo do artista é a PRESSUPOSIÇÃO, que é, talvez, o oposto do interesse. A primeira coisa que acabará com a obra de um artista é a pressuposição de saber o que está fazendo, de saber como andar e como falar, de que o que ele "quer dizer" significará a mesma coisa para os receptores. No instante em que você pressupõe quem é o público ou qual é o momento, este mesmo momento estará dormente.

Como diretora, sei que não é minha responsabilidade produzir resultados, mas sim criar as circunstâncias para que algo possa ocorrer. Os resultados virão por si mesmos. Sinto que isto é verdadeiro para todos os artistas criadores. Cuide bem da atitude, da atenção, da violência necessária, do controle físico e da expansão das emoções, do desequilíbrio e da desorientação, e do interesse. Depois, comece a trabalhar. 